\title{
A MARGINALIDADE ENQUANTO IDENTIDADE: A LITERATURA DE PERIFERIA E O EMPODERAMENTO CULTURAL DE SEUS SUJEITOS
}

\author{
THE MARGINALITY WHILE IDENTITY: THE PERIPHERIC \\ LITERATURE AND THE CULTURAL EMPOWERMENT OF THIS \\ SUBJECTS
}

\author{
${ }^{1}$ Lais Mendes Botelho das Neves; ${ }^{2}$ Jonas Anderson Simões das Neves \\ 1 lacka@bol.com.br, Universidade Federal de Rio Grande; \\ 2 jonasanderson@ig.com.br, Universidade Federal do Pampa.
}

\begin{abstract}
Resumo
O estudo da cultura brasileira se constitui numa área interdisciplinar e que envolve um número significativo de obras e autores, de forma que as abordagens propostas acabam selecionando apenas alguns considerados mais representativos, no entanto essas são escolhas arbitrárias e que comumente desconsideram as contribuições de vertentes marginais do pensamento e da sociedade. Desta forma, neste artigo pretende-se discutir acerca do lugar da Literatura marginal no interior do pensamento social brasileiro, destacando-se, neste sentido, seu espaço social e sua relevância enquanto dimensão capaz de colaborar com a construção da identidade das populações marginalizadas. Neste sentido, verifica-se que se inicialmente eram atribuídas conotações negativas a marginalidade, a partir da ocupação de um espaço de enunciação, essa foi ressignificada, sendo assumida pelos indivíduos marginais, escritores ou não, como dimensão construtora de sua identidade.
\end{abstract}

Palavras-chave: Marginalidade, identidade, Literatura.

\begin{abstract}
The study of Brazilian culture is an interdisciplinary area that involves a significant number of works and authors, so that the proposed approaches end up selecting only some considered more representative, however these are arbitrary choices and commonly disregard the contributions of marginal aspects of thought and society. Thus, this article aims to discuss about the place of marginal literature inside the Brazilian social thought, standing out in this sense, their social space and its relevance as a dimension capable of helping to build the identity of marginalized populations. In this sense, negative connotations it turns out that if they were initially allocated marginality, from the occupation of a statement of space, this was resignified, being assumed by marginal individuals, writers or not, as a dimension of their identity construction.
\end{abstract}

Palavras-chave: Marginality, Identity, Literature

\section{Introdução:}

Em artigo dedicado a analisar as tendências do pensamento social brasileiro, Ianni (2000) destaca as diferentes interpretações relativas ao Brasil desde sua fundação, utilizandose para isso da análise das obras de diferentes autores, de diferentes áreas e que se dedicaram a escrever sobre o país, categorizando-as segundo as abordagens propostas. No referido 
artigo, o autor caracteriza cada uma das tendências identificadas pelo pensamento apresentado pelos principais autores a elas identificados, de forma que algumas vertentes do pensamento social brasileiro, especialmente aquelas de menor alcance, acabam não sendo enfatizadas.

Considerando a vastidão e a riqueza do pensamento social brasileiro, bem como a proposta de um estudo abrangente acerca do tema, é compreensivo e mesmo plausível que se faça opções por aqueles autores e obras mais representativos. Contudo, neste tipo de análise algumas vertentes acabam por não serem contempladas, especialmente aquelas que, por diferentes motivos, acabam não chegando ou repercutindo no campo do que é definido enquanto intelectualidade. No entanto, tal como argumentam Schwarcz e Botelho (2011, p. 12-13) há, contemporaneamente, o entendimento de que o conhecimento está distribuído nos mais variados setores da sociedade, de forma que adquirem cada vez maior relevância os estudos acerca desta produção.

Esse é o caso da Literatura de periferia ou marginal, a qual é escrita por membros marginalizados na sociedade, ou seja, moradores da periferia que retomam suas vozes e começam a escrever suas próprias histórias sem intermediários, as quais eram retratadas, principalmente, por intelectuais advindos da classe média. Esse movimento, em última análise, representa o empoderamento da voz dos excluídos por eles mesmos.

Entendemos ser esse um movimento importante no que tange a compreensão e a construção do país a partir de sua intelectualidade, pois abre espaço para que aqueles que sempre estiveram presentes enquanto objeto no discurso e, consequentemente, nas decisões das elites que, direta ou indiretamente, governaram o país, possam também incluírem-se enquanto sujeitos dessa história da qual foram, concomitantemente, protagonistas empíricos e coadjuvantes teóricos.

\section{Discussão}

O estudo do pensamento social constitui-se numa área multidisciplinar, dado que nenhuma disciplina, autor ou agrupamento social possui a prerrogativa de exclusividade sobre a interpretação da sociedade, por mais que isso possa acontecer em alguns casos. Desta forma, a própria vertente da marginalidade periférica que se destaca neste artigo constitui-se a partir das interfaces entre as diferentes áreas do conhecimento.

Para pensarmos acerca da marginalidade cabe fazermos uma breve reflexão sobre esse termo e seu significado. Segundo Schmitt (1988, p. 264) há certa dificuldade de uma definição do que é marginal, mas algumas noções podem ser esclarecidas, tais como a de que a marginalidade "implica um estatuto mais ou menos formal no seio da sociedade e traduz 
uma situação que, pelo menos teoricamente, pode ser transitória.” Essa questão da transitoriedade do estado "marginal" para o integrante pleno da sociedade pode ser vislumbrada em diferentes casos no texto de Schmitt, o qual fala que as cidades foram, na sociedade feudal, um corpo marginal e que dela faziam parte esses membros indesejados. $\mathrm{O}$ autor ainda destaca ao longo do tempo outros grupos que sofreram com algum tipo de estigma, como os açougueiros, os operários da indústria têxtil, as prostitutas, os "usurários", os judeus, os ciganos, os leprosos e os criminosos.

Dentre os grupos citados pelo autor, podemos perceber que alguns foram "incluídos" completamente na sociedade, mas sobre outros ainda pairam as sombras desse passado que hoje se manifesta, principalmente através do preconceito. Outra implicação desse estatuto marginal é o apagamento das vozes dessas pessoas, ou seja, suas vozes nunca fizeram parte do discurso oficial, da construção da história, pelo contrário, até bem pouco tempo se omitia quase que totalmente sua existência. Em seu texto, Schmitt fala da dificuldade de ouvir esses marginais do passado e que

Ela [a voz dos marginais] foi sistematicamente abafada pelos detentores do poder, que não falavam dos marginais, mas não os deixavam falar. Chegar diretamente ao que os marginais diziam, sem passar de uma maneira ou de outra pela mediação de um discurso oficial ou erudito, é uma empresa quase desesperada. (SCHMITT, 1988, p. 284).

No que diz respeito ao Brasil, a questão do ser marginalizado também esteve sempre presente, num primeiro olhar a partir de dimensões étnicas, como acontece com negros, indígenas, mestiços e seus descendentes, mas de maneira mais velada e enfática, quando se trata do que Souza (2009) chama provocativamente de ralé brasileira, ou seja, a parcela da população brasileira que está afastada das benesses do capital e do estado, mas que, ao mesmo tempo, é a principal responsável pela geração do primeiro e pela manutenção do segundo, lutando diariamente por sua sobrevivência, sendo, por isso, também definida pelo mesmo autor através expressão "batalhadores".

É importante destacar que a marginalidade na sociedade contemporânea não é produto apenas da dimensão étnica ou econômica dos indivíduos, mas tende a ser um produto destas associadas a outros fatores, tais como ocupação, escolaridade, local de moradia, entre outros. Isto ocorre porque o fenômeno da marginalidade é decorrente da própria lógica de organização capitalista, que constitui a riqueza de poucos a partir da exploração da maioria, bem como está relacionada ao processo de formação do estado brasileiro. 
Desta forma, desde a chegada dos portugueses ao território brasileiro houve a organização de um sistema produtivo voltado ao enriquecimento do país europeu. Neste sistema, tanto as populações locais quanto os escravos africanos trazidos a força para o continente americano foram incorporados apenas como meios de produção, numa situação que ainda hoje se reproduz, apesar dos avanços alcançados no que se refere a regime de trabalho, direitos sociais, legislação, etc. Com isso não se quer dizer que a situação do escravo é semelhante a do trabalhador livre dos dias de hoje, mas sim que as classes subalternas e marginalizadas de hoje são, em boa medida, descendentes daquelas dos séculos anteriores, bem como que as elites também continuam sendo as mesmas.

Da mesma forma, também é importante destacar que esse fenômeno de reprodução das classes sociais não está relacionado apenas a fatores econômicos, mas que tem relação direta com outras implicações deste, tal como o acesso a esfera política e ao próprio universo do pensamento social, tal como a abordagem que se está propondo neste texto. Nestes termos, as elites brasileiras também foram responsáveis pela formação da intelectualidade brasileira que, de uma ou outra forma, acabou por reproduzir e legitimar "cientificamente" suas bases ideológicas de dominação, de forma que as mesmas acabam por legitimar desigualdades a partir do momento em que se tornam diretrizes para o ensino, para decisões judiciais, para ações públicas e privadas e para a própria "ralé", a partir do momento em que esta aceita como verdadeira uma identidade marginal pejorativa que lhe é atribuída pelos outros. (SOUZA, 2015)

Sendo assim, a sociedade adota como verdade discursos, produzidos por uma elite que possui recursos para investir em formação intelectual e na publicação de suas ideias, ampliada ainda mais pela popularização dos meios de comunicação, também sob seu controle. É neste cenário que se torna relevante o reconhecimento e a legitimidade das manifestações, em âmbito cultural e/ou intelectual, da "marginalidade", pois se suas ideias estiveram excluídas do pensamento social ao longo da história, esse espaço adquire proeminência enquanto lugar de enunciação, dado que, se enquanto silenciados apenas sofreram as conseqüências de um pensamento elitista, enquanto autores colocam no campo de jogo suas ideias e perspectivas, para que sejam também discutidas e incluídas na agenda da construção do país.

No Brasil, a ideia de marginalidade é inicialmente utilizada para analisar a precariedade habitacional em que se encontram alguns sujeitos sociais; mas, num segundo momento também assume outros matizes: 
Acrescenta-se a abordagem físico-ecológica [...] e cultural. Do habitat passa-se para a maneira de viver e para uma situação de vida. Baixo nível de renda e educação, subemprego e desemprego, desorganização familiar, anomia, falta de participação social. (KOWARICK, 1985, p.14)

O autor ainda contribui positivamente para uma reflexão mais ampla quando afirma que "a marginalidade é categorizada como uma falta de algo que existe no setor "evoluído"” (KOWARICK, 1985, p.59) e ainda, que "este conjunto de teorias parte da constatação de que a marginalidade é inerente ao sistema capitalista" (KOWARICK, 1985, p.61). Isso nos faz pensar que sempre existirá alguém que não estará contemplado nem terá suas necessidades supridas, e que o sistema sempre favorece este acontecimento.

Ao partir para a área da literatura, é possível perceber o uso da designação de "Literatura marginal" em diferentes momentos da nossa história literária e em diferentes contextos, como, por exemplo, no fim dos anos 1960, quando aparece ligada à contracultura e voltada ao tropicalismo, com as poesias de Waly Salomão. Também na poesia dos anos 1970 e com a literatura escrita atualmente nas periferias do Brasil, a qual também foi denominada de "Marginal" por Ferréz.

A partir dos anos 1970 um grupo de jovens se reuniu na busca de expressar seus anseios, dúvidas e medos, tendo como meio a poesia, um dos gêneros que deixa um viés de ampla liberdade. Os poetas que fizeram parte dessa gama de escritores se identificam com o termo "marginal" principalmente pelo viés da editoração, pois suas produções fogem dos padrões normais de editoração, circulação e distribuição.

O professor Schollhammer (2000, p. 2) identifica outro grupo de "marginais", o qual denominou "geração 90", definindo esse grupo como sendo composto de homens, em sua maioria paulistas, todos de uma mesma orientação literária. Foi uma maneira de dar manifestação a autores que não tinham conquistado uma visibilidade. Esses autores escrevem em diferentes gêneros e temáticas, em forma de romance e de miniconto, além dos que fazem parte do chamado novo regionalismo, sendo que o autor inclui ainda a literatura de periferia, através obra de Paulo Lins. Apesar da pretensa homogeneização pretendida pelo professor, os autores que fazem parte dessa geração são muito heterogêneos entre si. Sua produção foi intitulada marginal por conta apresentarem a voz dos excluídos e também, de alguma forma, pelo gênero de que se valiam, como no caso do miniconto.

A literatura de periferia surge no contexto cultural brasileiro nos anos 1960, a partir da publicação da obra Quarto de despejo, de Carolina Maria de Jesus. Esta autora era mãe solteira, catadora de papel e vivia na favela do Canindé/SP, tendo publicado ainda Casa de 
alvenaria (1961); Pedaços de fome (1963); Provérbios (1963) e Diário de Bitita (1982), póstumo. Foi somente cerca de trinta anos após a primeira publicação do gênero que outros dois autores vinculados à Literatura Marginal receberam novamente algum destaque: Paulo Lins, com as obras Cidade de Deus (1997) e Desde que o Samba é Samba (2012) e Ferréz, com Capão Pecado (2000); Manual prático do ódio (2003) e Deus foi almoçar (2012). Cabe destacar que estes não foram os únicos autores vinculados a Literatura Marginal no período, bem como que, tampouco, sejam apenas essas suas obras.

Afim de pensarmos a respeito da Literatura marginal ao longo de nossa história literária, a princípio recorreremos a Robert Ponge, em uma palestra sua transcrita na forma de artigo, na qual levanta a problemática da definição de termo "marginal", no ano de 1981. O autor reclama a necessidade de serem desenvolvidas pesquisas permitindo uma caracterização científica e menos impressionista da literatura intitulada marginal.

Ponge levanta a questão de que definir Literatura marginal como a que está "a margem" da literatura oficial, isto é, da dominante, não resolveria para uma distinção entre essas duas literaturas. Para pensar sobre o que pode caracterizar uma literatura como “marginal”, o autor faz uma série de questionamentos, entre eles estão:

Seria o número de livros vendidos? Seria a composição social dos leitores? Seria a classe social (ou até, a classe social de origem) do escritor? Seriam os temas tratados?seria a forma? Seria a língua? Seria a editoração? Seria o enfoque, o ponto de vista? (PONGE, 1981, p. 138)

Após dar alguns exemplos de diferentes formas literárias tanto no Brasil quanto na França, utilizando-se de suas questões como guias, o autor chega a uma ideia sobre o que seria, em termos gerais, essa literatura, afirmando que a Literatura marginal é, “[...] reflexo de uma falta de consenso a respeito do estado da sociedade e das saídas a propor. Se tivesse consenso, não existiriam produções que apareceriam como outras, como estranhas a classe dominante". (PONGE, 1981, p. 142).

No mesmo ano, Sergius Gonzaga profere uma palestra intitulada de Literatura Marginal, na qual trata a respeito da Literatura brasileira. Ao comentar sobre a grande quantidade de poetas e escritores que o Brasil vem produzindo, o autor explica que:

De certo modo, esse boom poderia ser explicado pelo autoritarismo vigente que, limitando a participação dos jovens na vida política, deixou-lhes aberta apenas a porta da Literatura para onde foram canalizados os anseio, os traumas e as verdades de uma geração. (GONZAGA, 1981, p.143) 
Gonzaga também se refere à multiplicidade nos discursos desses autores e que o traço que os liga é o termo "marginal", por autodefinição ou definição outorgada. Para ele, a categoria de "marginal" se apresenta em três instâncias, em virtude da forma como os diferentes grupos assim denominados se relacionam com o termo: "os marginais de editoração; os marginais de linguagem e os marginais por apresentarem a fala daqueles setores excluídos dos benefícios do sistema.” (GONZAGA, 1981, p. 149).

Em sua construção do conceito de "marginal", o autor recorre a sua acepção no sentido social, ou seja, aquelas pessoas que em decorrência do processo de desenvolvimento do país foram ficando de fora deste. Como, ao longo do tempo, as diferenças entre esses dois grupos distintos, os incluídos e os excluídos, só foram se acentuando, diferentemente do que, na época se acreditava que aconteceria, a marginalidade só se acentuou. Dessa forma, os que não conseguiam manter sua sobrevivência buscaram outras formas de se manterem, sendo assim o "Marginal tornou-se o ladrão, a prostituta, o mendigo, o menor abandonado, etc." (GONZAGA, 1981, p. 148)

Em seu texto podemos perceber que nos anos 80 já se estava abrindo uma brecha para uma literatura fora dos moldes tradicionais, esse era um momento do seu aparecimento e mantenimento. Segundo Gonzaga, "forma-se um leque de possibilidades para os produtores, fato que não ocorria, vamos dizer, há cinco anos atrás. Isso comprova que o tempo (...) altera e redimensiona todas as coisas.”(GONZAGA, 1981, p.153).

O que se pode inferir é que a Literatura de periferia, a qual passou a incidir no mercado brasileiro a partir dos anos 90, teve a possibilidade de inserção no mercado editorial, também pelo que nos anos 80 foi a abertura para as obras escritas pela classe média acerca dos excluídos. Com o conhecimento destas obras o público desenvolveu um interesse sobre o que os "excluídos" poderiam estar escrevendo.

No texto Intelectuais x Marginais Heloísa Buarque de Hollanda (2005) fala a respeito da passagem da voz dos setores excluídos da sociedade para eles próprios, ou seja, com o aparecimento de diversos movimentos advindos da periferia como o hip hop, a Literatura marginal os intelectuais de classe média perderam o espaço de mediadores entre o discurso dessas pessoas e a cultura letrada. Segundo a autora

Tradicionalmente, nós, intelectuais sempre fomos os porta-vozes das demandas populares e protagonistas dos movimentos de transformação [...] social na área dos projetos artísticos e literários. Hoje, parece que alguma coisa bastante diferente está no ar e que vamos ter que repensar, com radicalidade, nosso papel como intelectuais tanto no campo social como no acadêmico e artístico. (HOLLANDA, 2005, p.1) 
Sergius Gonzaga (1981, p.149) já se referia a essa distância entre o intelectual letrado e a matéria de seu discurso e sua exclusão do processo artístico no qual tinha como referência: "os legítimos marginais [...] continuam fora do processo de fatura artística de ordem letrada". E continua mostrando o que representava na vida e no cotidiano dessas pessoas serem transformados em matéria literária "Os ladrões roubam, as prostitutas transformam o corpo em valor de troca, os pivetes correm pelas ruas, indiferentes aos textos que os erigem como temática maior" (GONZAGA, 1981, p.149 - 150).

Heloísa Buarque de Hollanda fala de uma nova produção que de uma forma original, mescla entre o documental e o literário e que retrata de forma contundente a violência e a miséria, que segundo a autora se inaugura com dois autores oriundos da classe média e que vai se desenvolver de forma autônoma e com grande força, são eles: Zuenir Ventura, autor de Cidade partida (1994), que tem como tema as ações pós-massacre de Vigário Geral, e Drauzio Varella, com Estação Carandiru (1999), que retratava as condições subumanas de vida no maior presídio da América Latina.

Um fato interessante é que apesar de apontá-los como os precursores dessa nova forma narrativa a autora se refere à publicação de Cidade de Deus, de Paulo Lins, dois anos antes de Drauzio, mas não atribui a sua obra o mesmo lugar que as outras. E ainda se refere a ele como uma "variável totalmente imprevista nos nossos círculos literários: o pobre tem voz e pode até escrever; e mais ainda: escrever um livro com sucesso de público e de crítica." (HOLLANDA, 2005, p.2). Isso demonstra sua impossibilidade de quebrar com a tradição da primazia intelectual advinda da classe média, que transparece na utilização do termo "até", ou seja, demonstrando surpresa com o fato de um pobre conseguir escrever um texto de boa qualidade, como se a pobreza, por si só, fosse sinônimo de incapacidade e não de falta de oportunidades.

Gonzaga ainda adverte sobre o perigo de escrever acerca dos "setores não inseridos no sistema" e dá o que seria uma resolução para o problema, na qual diz que seria melhor que os filhos dos operários, os quais já estariam se alfabetizando, escrevessem sobre a difícil vida deles e de seus pais. Dessa forma, podemos ver que nessa época, em torno dos anos 1980, os pobres ainda não escreviam e não tinham nenhum tipo de espaço.

No que diz respeito à problematização do lugar dos intelectuais, feita por Heloisa Buarque de Holanda, esta pode ser confirmada na proposta de Ferréz, um dos mais significativos nomes em termos de produção do povo, dado que esse autor traz muitas vezes o discurso dessas pessoas simples que querem escrever, que querem mostrar o seu trabalho. 
$\mathrm{Na}$ coletânea que organizou de autores da periferia, Ferréz escreveu um texto de abertura chamado Terrorismo literário, no qual podemos perceber sua postura com relação à produção desses escritores. Estes se submeteram por muito tempo a algum tipo de mediação, para poderem publicar suas obras, como Carolina Maria de Jesus, ou ainda para obterem certo reconhecimento, como Paulo Lins. Num viés de livre expressão e de um lugar reconhecido para esses escritos ou livros é que se refere Ferréz:

...não somos movimento, não somos os novos, não somos nada, nem pobres, porque pobre segundo os poetas da rua é quem não tem as coisas. Cala a boca, negro e pobre aqui não tem vez! Cala a boca! Cala a boca uma porra, agora a gente fala, agora a gente canta, e na moral agora a gente escreve. Quem inventou o barato não separou entre literatura boa/feita com caneta de ouro e literatura ruim/escrita com carvão, a regra é só uma mostrar as caras. (FERRÉZ [Org], 2005, p. 09)

Ao lermos o texto escrito por Ferréz percebemos a agressividade como forma de se libertar, nesse caso dos mediadores, dos outros escritores, e até mesmo do preconceito contra os escritores advindos da periferia, e também nos deparamos com sua face ativista, a qual se mostra em suas crônicas e em suas entrevistas. Como podemos observar, para o autor todos têm o direito de escrever e isso independe de quem quer que seja, e que eles, os escritores da periferia, não vão deixar de mostrar suas vozes.

Dessa forma, podemos entender o gigantesco salto da literatura que se estava muito embrionariamente produzindo nos anos 1980 para a dos 1990 e que se estende até hoje. Gonzaga tinha como pretensão a escrita dos filhos dos operários, mas não tinha como imaginar que além desses filhos de operários, também outros viriam a escrever, filhos de empregadas domésticas, de pedreiros e daqueles que não conseguem uma ocupação fixa e dão o sustento a sua família realizando toda e qualquer tarefa que lhes é proposta.

A evolução no que diz respeito ao interesse sobre a literatura desses autores se deu em uma grande parte, pela perseverança em criar um espaço para suas obras, o qual não existia. Assim, foram ganhando reconhecimento e com isso, o papel de mediador ou intelectual foi cada vez mais deixado de lado.

As obras escritas por moradores da periferia vêm cada vez mais ganhando relevo, principalmente pelo interesse de pessoas como Ferréz e Sérgio Vaz, presidente da Cooperifa e escritor. Essas pessoas, a partir de sua visibilidade e reconhecimento, desenvolvem atividades nas quais são abertas as possibilidades dos escritores estreantes mostrarem seus trabalhos, como nas rodas de leituras e saraus. Nesses eventos são chamadas, além de pessoas das 
próprias comunidades, também gente de toda a parte, havendo uma interação e divulgação desses textos.

Outro ponto interessante é a criação de editoras que publicam somente a obra desses autores que moram na periferia e que muito dificilmente conseguiriam lançar suas obras em uma grande editora logo no começo de suas carreiras, são elas a Edições Toró e Selo do Povo. Algo a destacar é que os livros das edições Toró são feitos de uma forma bem artesanal, usam tecidos ou objetos para compor as capas, também é interessante o tipo de fonte das letras que são usadas, essas são das mais variadas, são menos tradicionais. Isso demonstra o caráter original dessas obras. Além disso, a editora também organiza eventos para os lançamentos, nos quais outros escritores também podem mostrar suas obras.

Desse modo, podemos perceber que o fenômeno da Literatura marginal escrita por moradores de periferia vem se mantendo firme e cada vez mais sólido, pois além do interesse inicial que despertou na população, com as obras escritas sobre esses lugares, há um grande esforço, trabalho e organização no sentido de que esses autores possam manter seu direito de escrever e o mais importante, de serem lidos, dentro e fora de suas comunidades.

Desta forma, o que se tinha, antes da ascendência e do reconhecimento dos marginais enquanto produtores de cultura, é que os mesmos, em suas diferentes formas, apareciam no pensamento social apenas enquanto discurso construído pelo outro, adquirindo, dessa forma, também uma identidade que lhes era atribuída por outros, que falavam em seu nome e a seu respeito sem vivenciarem a sua condição. Esta identidade social virtual, para usar o vocabulário de Goffmann (1988, p. 13), que caracteriza negativamente os marginalizados também chegava até eles, que em alguma medida a incorporam, fazendo com que se torne integrante de sua identidade social real.

No entanto, a partir do momento em que os marginais passaram a ocupar um lugar enquanto produtores de cultura e conseguiram criar e afirmar um lugar de enunciação de suas vivências e perspectivas gerou-se uma cisão na ordem estabelecida, surgindo a necessidade de um reordenamento das hierarquias intelectuais. Neste sentido, por mais que tenha sido a contragosto dos intelectuais tradicionais, vinculados às elites e classes médias, os antes marginalizados inseriram-se em seu meio, reivindicando seu direito de também estarem lá, num processo que também inspirou e ressignificou as bases da marginalidade, pois o marginal deixa de ser o sujeito passivo e inferiorizado que está às margens da sociedade para se tornar o sujeito ativo que luta por seus espaços e exige ser tratado de forma igual, independente de cor, classe econômica, lugar de moradia ou o que quer que seja. 
Obviamente, este não é um fenômeno exclusivo do Brasil e de sua esfera cultural, dado que a própria modernidade ocidental também foi caracterizada por esse processo de tomada dos espaços de expressão pelos grupos dominantes, que falavam em nome de si e dos dominados. É foi também neste mesmo sentido que os estudos pós-coloniais surgiram destacando a necessidade de que os indivíduos marginalizados ocupassem também um espaço de enunciação, utilizando a marginalidade enquanto ponto de vista hermenêutico e mesmo como espaço de luta, dada sua legitimidade para falar sem a intermediação de terceiros. (BHABHA, 1998, p. 347; GILROY, 2001, p. 397)

Nestes termos, ganham relevância as manifestações culturais dos marginais, pois são elaboradas pelos próprios marginalizados e possuem a capacidade de permitir a criação de uma identidade positiva. De acordo com Dubar (1998), a identidade é construída a partir de uma perspectiva dual, que põe, de um lado, uma identidade de si - construída subjetivamente pelo ator - e, de outro, uma identidade para si - construída na e pela relação com o outro. Neste sentido, o marginalizado já possui, mediante o olhar do outro, uma identidade negativa, dada a estigmatização de sua condição social, de forma que é indispensável que, ao menos, a identidade de si possua conotações positivas, o que pode ser possibilitado pela existência de uma cultura, da qual a literatura é importante manifestação, produzida pelos próprios marginais e que valorize sua experiência cotidiana. Mais do que isso, a valorização da cultura marginal ressignifica o próprio olhar do outro, no sentido de que se passa a reconhecer a legitimidade das demandas do marginal. Não por acaso jovens de classe média já ouvem o som e vestem a moda da periferia, alguns por adesão a causa, outros por modismo, mas, de toda forma, ressignificando o olhar da sociedade diante das expressões mais visíveis da cultura periférica.

Paul Gilroy (2001, p. 407) salienta a importância de uma arte produzida pelos indivíduos marginalizados, destacando o romance, através da qual eles possam reformular e conservar sua memória histórica. O autor cita o exemplo da experiência de autores negros, que tornaram a escravidão inteligível e legível na/pela mediação da escrita. (GILROY, 2001, p. 409-410). Gilroy (2001, p. 405) ressalta ainda que, ao mesmo tempo em que o terror esgotou os recursos linguísticos dos escritores negros, é fundamental que os mesmos continuem escrevendo, pois são os seus textos o amálgama capaz de permitir a conformação de uma rede de identidades.

Bhabha corrobora esta necessidade de uma escrita por parte dos marginais, argumentando ainda que este tipo de literatura deva carregar em si também um caráter testemunhal, através do qual tais populações possam construir e representar uma ideia de 
agência, falando "da realidade da sobrevivência e da negociação que constitui o momento de resistência, sua tristeza e sua salvação”. (BHABHA, 1998, p. 351)

Os autores pós-coloniais (BHABHA, 1998; GILROY, 2001; HALL, 2003) vêm denunciado sistematicamente à escrita de uma história de progresso a partir de um ponto de vista Ocidental que, mais do ignorar as contribuições dos marginalizados, tem se calado em relação ao "ser em estado de dor" que caracterizou tais populações. Neste sentido, Gilroy (2001, p. 397) argumenta que, mais do que a própria necessidade de uma escrita marginal, há a necessidade de que tais escritores façam uso das vantagens da marginalidade como um ponto de vista hermenêutico.

Bhabha identifica a existência de um entre-tempo, ainda aberto, entre o passado colonial e a modernidade pós-colonial, o qual pode ainda ser estrategicamente ocupado pelos marginais, linguisticamente empoderados, permitindo-lhes assumir o papel de agentes ativos da tradução de suas próprias experiências históricas, sem a necessidade de mediadores. (GILROY, 2001, p. 397)

Neste sentido, os marginais comporiam um novo espaço enunciativo da modernidade, tão legítimo quanto os demais e capaz de permitir-lhes construir, sem mediações, seu espaço na elaboração da modernidade. Bhabha destaca ainda que, com a prerrogativa deste espaço enunciativo, a história dos marginais seja inscrita como uma narrativa histórica da alteridade, representando e incluindo as identidades marginais, em constante processo de hibridização, em pé de igualdade na construção de uma outra modernidade. (BHABHA, 1998, p. 347)

No caso brasileiro a construção discursiva dos marginais, relato de suas experiências, manifestas na literatura por eles produzida, pode ser interpretada no sentido proposto por Oliveira, quando este argumenta em favor da necessidade de que a luta pela cidadania, seja deslocada do front econômico, onde os marginais estariam fragilizados, para os fronts da política e da sociedade civil, na qual estaria contemplada a dimensão cultural, na qual está situada a literatura. (OLIVEIRA, 2001, p. 28)

Oliveira vai ainda mais longe, argumentando que a cidadania é a forma mais acabada da luta de classes atual, estando sua expressão na "luta pelos significados, pelo direito à fala e à política, que se faz apropriando-se do léxico dos direitos e levando-os, redefinindo-os, num novo patamar, de fato transformando o campo semântico ao tempo em que se apropria dele”. (OLIVEIRA, 2001, p. 21)

Desta forma, é num campo específico da sociedade civil que os marginais têm, através da Literatura Marginal, empreendido sua luta que, mais do que por cidadania ou melhores condições de vida, é por seu reconhecimento enquanto agentes capazes de expressarem sua 
própria experiência cotidiana e histórica sem a necessidade de mediadores. Mais do que isso, esta luta se refere à construção de um espaço de enunciação legitimamente reconhecido e capaz de permitir a inclusão, em pé de igualdade, dos marginais num outro projeto de modernidade.

Esta perspectiva de busca por um espaço de enunciação que se constitua, simultaneamente, em uma dimensão hermenêutica e numa dimensão de luta, pode ser percebida num outro excerto do texto Terrorismo literário

\begin{abstract}
Não somos o retrato, pelo contrário, mudamos o foco e tiramos nós mesmos a nossa foto. A própria linguagem margeando e não os da margem, marginalizando e não os marginalizados, rocha na areia do capitalismo. [...] Somos mais, somos aquele que faz a cultura, falem que não somos marginais, nos tirem o pouco que sobrou, até o nome, já não escolhemos o sobrenome, deixamos para os donos da casa grande escolher por nós, deixamos eles marcarem nossas peles, porque teríamos espaço para um movimento literário? Sabe duma coisa, o mais louco é que não precisamos de sua legitimação, porque não batemos na porta para alguém abrir, nós arrombamos a porta e entramos. (FERRÉZ [Org], 2005, p. 09)
\end{abstract}

Percebe-se ainda no fenômeno da Literatura marginal a presença do que Anjos (2002, p. 243) denomina de marginalidade reivindicada, ou seja, na busca pela legitimidade de seu espaço de enunciação os marginais reivindicam para si a "marginalidade" que lhes era atribuída pelos outros, mas a ressignificam. Desta forma, a própria marginalidade de que são sujeitos os empodera, permitindo que sejam reconhecidos enquanto marginais, não mais pelas características negativas atribuídas ao conceito, mas pelas prerrogativas positivas que arrogam a marginalidade e ao ser marginal.

\title{
3. Considerações finais
}

O processo de formação e afirmação de um povo ou país está diretamente relacionado à forma como este é discursivamente construído, no entanto este processo tende a ser um dos produtos da própria forma como se organizam as relações sociais, econômicas e políticas em seu interior. Desta forma, tendem a predominar no pensamento social as ideias dos grupos que possuem a hegemonia nestas esferas, mesmo porque, como nos lembra Gramsci, a primeira batalha a ser vencida na luta pela hegemonia da sociedade é aquela travada no campo das ideias, a fim de que a dominação se torne legitima entre os dominados, não apenas pela coerção, mas também pela coação ideológica. (PORTELLI, 1977)

Da mesma forma, identifica-se no pensamento social brasileiro a constância desta ordem, dado que se inicialmente o mesmo foi caracterizado pela importação de conceitos dos colonizadores europeus, na etapa seguinte permaneceram intrinsecamente imbricados as 
formulações dos intelectuais vinculados à elite brasileira. No cenário destas construções interpretativas do Brasil, o lugar da população é sempre de coadjuvantes, que vivem e caracterizam o país, mas que não conseguem participar de sua construção, tal como podem ser exemplo o "homem cordial", o "Jeca Tatu", "Gabriela”; ou ainda imagens construídas sob a perspectiva da elite, tais como o "paraíso racial" ou o país do "samba e do futebol"; entre tantas outras imagens feitas pela intelectualidade brasileira.

É neste sentido que se coloca a perspectiva da marginalidade periférica, pois a população que não se vê no discurso do outro passa a construir também um discurso no qual se inclui, não mais de maneira estereotipada ou idealizada, mas a partir da realidade que vivencia. Neste movimento, enquanto a intelectualidade - filha da elite que a construiu - reluta em reconhecer a legitimidade dos autores e do espaço de enunciação que foi ocupado pela marginalidade -, os batalhadores, para usar o termo de Jessé Souza, aderem a ela, por sua identificação a mesma, afinal de contas nela não são apenas os ladrões, prostitutas, traficantes ou empregados(as) com papel secundário, mas são os protagonistas que constroem as histórias.

Este lugar de enunciação ocupado pelos marginais ainda não foi completamente reconhecido e incluído no âmbito do pensamento social brasileiro, ainda elitizado, mas, por sua vez, está conseguindo chegar ao âmago da sociedade, tal como pode ser observado pela adesão de suas obras por parte de grandes editoras, produtoras cinematográficas e demais mídias de grande circulação, a despeito das controvérsias que esta adesão tem causado no interior das discussões acerca da marginalidade. Não cabe aqui adentrar neste debate, mas importa analisar algumas possíveis implicações desta maior inserção da perspectiva marginal nestes veículos, tais como o reconhecimento desta população e de suas demandas.

Além disto, a produção cultural dos marginais possui ainda outra importante contribuição, pois se a esfera cultural é um dos espaços no qual se reproduz a dominação, dado que é reproduzida pelas escolas, pelo poder público, pelo judiciário, pelo legislativo, entre outros; a partir do momento em que sua perspectiva passa a fazer parte da cultura brasileira, mesmo que sem o reconhecimento dos intelectuais tradicionais, suas idéias também passam, em alguma medida, a compor a agenda das discussões em torno das diretrizes de desenvolvimento do país.

Desta forma, se inicialmente a marginalidade esteve presente na produção cultural brasileira enquanto designação pejorativa e reificada das esferas menos favorecidas da sociedade brasileira, a partir da ascendência da Literatura de periferia, passa a ser assumida pelos próprios marginais, mas a partir de uma perspectiva ressigificada, de forma que se 
constitui na própria conformação da identidade dos marginalizados. No entanto, para além de sua representatividade em termos culturais e literários, há de se destacar que a ressemantização do conceito saiu das páginas dos livros para as esquinas das periferias, de forma que os indivíduos marginalizados, não fictícios, também avocam para si essa identidade marginal que os empodera enquanto sujeitos.

\section{Referências}

ANJOS, Gabrielle dos. Homossexualidade, direitos humanos e cidadania. Sociologias, Porto Alegre, ano 4, nº 7, Jan/Jun 2002, p. 222 - 252.

BHABHA, Homi. O local da cultura. Belo Horizonte: Editora da UFMG, 1998

DUBAR, Claude. Trajetórias sociais e formas identitárias: alguns esclarecimentos conceituais e metodológicos. Campinas, Educação \& Sociedade. V. 19, N. 62, abril, 1998.

FERRÉZ. Terrorismo literário. In: Ferréz (Org) Literatura Marginal: Talentos da escrita Marginal. Rio de Janeiro: Agir, 2005.

GILROY, Paul. O Atlântico Negro: modernidade, e dupla consciência. Rio de Janeiro: Editora 34, 2001.

GOFFMAN, Erwin. Estigma: notas sobre a manipulação da identidade deteriorada. Rio de Janeiro: LTC, 1988.

GONZAGA, Sérgius. Literatura marginal. In FERREIRA, João Francisco (Org.). Crítica literária em nossos dias e literatura marginal. Porto Alegre: Ed. da UFRGS, 1981.

HOLLANDA, Heloísa Buarque de. Intelectuais x Marginais. In Portal Literal, 1985 disponível em HTTP://www.portalliteral.com.br/artigos/intelectuais-X-marginais acesso em 10 de Agosto de 2011.

IANNI, Octávio. Tendências do pensamento brasileiro. Tempo Social, Revista de Sociologia da USP, São Paulo, 12 (2), 55-74, Novembro de 2000.

KOWARICK, Lúcio. Capitalismo e marginalidade na América Latina. Rio de Janeiro: Paz e Terra, 1985.

OLIVEIRA, Francisco de. Aproximações ao enigma: o que quer dizer desenvolvimento local? São Paulo: POLIS/Programa Gestão Pública e Cidadania/EAESP/FGV, 2001.

PORTELLI, Hugues. Gramsci e o bloco histórico. Rio de Janeiro: Paz e Terra, 1977.

PONGE, Robert. Literatura marginal: tentativa de definição e exemplos franceses. In: FERREIRA, João Francisco (Org.). Crítica literária em nossos dias e literatura marginal. Porto Alegre: Ed. UFRGS, 1981. 
SCHOLLHAMMER,Karl Erik. Literatura brasileira contemporânea. São Paulo: Civilização, 2000.

SCHWARCZ, Lilia; BOTELHO, André. Pensamento social brasileiro, um vasto campo ganhando forma. Lua Nova, São Paulo, 82, 11-16, 2011.

SOUZA, Jessé. A ralé brasileira: que é e como vive. Belo Horizonte: Editora da UFMG, 2009.

SOUZA, Jessé. A tolice da intelectualidade brasileira. Rio de Janeiro: Casa da Palavra, 2015. 